\title{
Regulated expression at high copy number allows production of a growth- inhibitory oncogene product in Drosophila Schneider cells
}

\author{
Hanne Johansen, ${ }^{1,3}$ Ariane van der Straten, ${ }^{1}$ Ray Sweet, ${ }^{1}$ Edward Otto, ${ }^{2}$ Gustavo Maroni, ${ }^{2}$ and \\ Martin Rosenberg ${ }^{1}$ \\ ${ }^{1}$ Biopharmaceutical Research and Development, Smith Kline \& French Laboratories, Research and Development Division, \\ King of Prussia, Pennsylvania USA; ${ }^{2}$ Department of Biology and Curriculum in Genetics, University of North Carolina, \\ Chapel Hill, North Carolina USA
}

The Drosophila metallothionein promoter (Mtn) was used to obtain efficient, regulated expression of foreign gene products inserted in high copy numbers into Drosophila melanogaster Schneider 2 cells. An expression unit comprised of a reporter gene [Escherichia coli galactokinase (galK)] fused to the Mtn promoter was stably introduced into Schneider 2 cells in up to several hundred copies per cell in a single transfection-selection event. This system contrasts dramatically with other eukaryotic systems that permit only a few copies of a gene to be stably inserted in a single transfection-selection event. The transfected Drosophila S2 cell lines expressed high levels of both galK mRNA and protein in response to metal induction. Most important, and in contrast to mammalian cells, expression remained fully regulated even at high copy number, with low basal expression maintained in the absence of inducer. This regulated system was used to obtain efficient expression in Drosophila cells of an otherwise lethal or growth-inhibitory gene product, the human H-ras oncogene. The ability to obtain regulated high-level expression of potentially lethal foreign proteins is unique to the Drosophila cell system.

[Key Words: Gene regulation; high copy number; oncogene; insect cell]

Received January 26, 1989; revised version accepted April 7, 1989.

Metallothioneins (MTs) are low-molecular-weight, cysteine-rich proteins that bind heavy metals. Although their complete physiological role is not yet known, they appear to protect cells against toxic metals and may be involved in homeostatic regulation of essential metals such as copper and zinc (Hamer 1986; Kagi and Kojima 1987; Karini et al. 1983; Otto et al. 1986). In mammals, there are multiple MT genes whose transcription is regulated by heavy metals (Brinster et al. 1982; Durnam et al. 1981; Hamer and Walling 1982; Karin et al. 1984). Several of these genes have been cloned and were found to retain their metal-regulated expression following transfer at low gene copy number into heterologous animal cells (Hamer and Walling 1982; Mayo et al. 1982; Searle et al. 1984; Otto et al. 1987). Two MT genes Mtn and Mto have been isolated from Drosophila melanogaster. The complete nucleotide sequence of Mtn has been determined, and its regulatory elements have been identified (Lastowsky-Perry et al. 1985; Maroni et al. 1985; Otto et al. 1987). Recently, it was demonstrated that a chimeric Drosophila gene driven by the Mtn pro-

${ }^{3}$ Corresponding author. moter was transcriptionally regulated when introduced into cultured Drosophila cells (Bunch et al. 1988). The Mtn gene was also introduced into Drosophila flies, as well as into baby hamster kidney cells, and was found to retain metal-regulated expression in both systems. However, the relative activity of the Drosophila Mtn promoter in hamster cells was only $5 \%$ of the mouse MT-I promoter in the same system.

The mouse metallothionein I (MT-I) promoter region has been used to express a variety of mammalian gene products in cultured mouse cells. For example, genes encoding human growth hormone, hepatitis B surface antigen, and influenza hemagglutinin, have been fused to the regulatory sequences of the MT-I gene on bovine papilloma virus vectors and expressed at high levels $(\mathrm{Pa}-$ valakis and Hamer 1983; Hsiung et al. 1984; Sambrook et al. 1985). Expression from an exogenously introduced MT-I promoter also has been monitored transiently in R1610 hamster cells and C127 mouse cells and found to give only a 4- to 5-fold increase in expression when fully induced with heavy metals (Pavalakis and Hamer 1983; Johansen et al. 1984), whereas the endogenous singlecopy gene reaches induction levels of up to 50 -fold. Ap- 
parently, introducing the promoter at higher copy number results in increased basal levels of expression, which, in turn, result in loss of regulation and increased constitutive expression.

In this paper we investigate the efficiency and regulation of the Drosophila Mtn promoter in Drosophila S2 cells and the use of Mtn to express foreign genes in Drosophila cell culture in a regulated manner. We demonstrate that, in contrast to mammalian systems, the Drosophila Mtn promoter can be used to obtain regulated, efficient, and stable expression of genes introduced into Drosophila cells at high copy number in a single transfection-selection event. This system permits selective and regulated expression of gene products that may exhibit lethal or growth-retarding effects when expressed. We demonstrate the application of this system to the regulated expression of the proto-oncogenic and oncogenic forms of the human H-ras gene in Drosophila cells.

\section{Results and discussion}

Stable integration of a pMtn-directed transcription unit at varying copy number

To characterize the function of the Drosophila Mtn promoter in Drosophila cells, we fused it to a reporter gene, Escherichia coli galactokinase (galK), and introduced it stably into Drosophila cells at varying copy number (Fig. 1). galK serves as a reporter gene in this cell type because no endogenous galK protein or activity is found in S2 cells (Kamerow et al. 1981). The vector carrying the pMtn-galK chimeric transcription unit was introduced into S2 cells by cotransfection with a second vector, which carries a selectable marker $E$. coli $d h f r$ gene (pHGCO), which confers resistance to methotrexate selection or carries the $E$. coli hygromycin B phosphotransferase gene (pcodhygro), which, in turn, confers resistance to hygromycin B. Either vector can be used to achieve stably integrated copies of transfected DNAs (Bourouis and Bruno 1983; Van der Straten et al. 1989). To achieve integration of high copy number of the galK gene, we used a ratio of $1: 1$ of the pMtK to pHGCO vector or a ratio of $10: 1$ of the $\mathrm{pMtK}$ to pcodhygro vector. For the following experiments, we used cotransfection with the pHGCO vector to obtain methotrexateresistant cell lines that contained different copy numbers of the pMtK vector DNA. Copy number was controlled by varying the ratio of $\mathrm{pMtK}$ to $\mathrm{pHGCO}$ DNA used in the cotransfection. Independent transfections were performed using $\mathrm{pMtK}$ to $\mathrm{pHGCO}$ ratios of $\mathrm{A}$ $1: 100$, B $1: 10$, and C $1: 1$. In each case, methotrexateresistant cell lines were generated, chromosomal DNA was isolated, and integrated sequences examined by genomic Southern blot analysis, using both galK- and $d h f r$-specific probes. The results show that cell lines selected at all three vector ratios contain both vector DNAs. Moreover the galK and dhfr copy numbers indeed varied in the three cell lines in proportion to the ratios of input DNA (Fig. 2, lanes 1-3). The three cell lines were estimated to contain $\sim 1-2,50$, and $\sim 500$ copies of the pMtn-galK transcription unit, respectively (Fig. 2, lanes 3, 2, 1). All three cell lines were passaged both with and without selection for several months in culture and reexamined by genomic Southern blot analysis. No change in copy number was observed, indicating that the sequences had been stably integrated into the host cell. We emphasize that this system allows for rapid selection of stable cell lines with varying copy number of exogenously introduced sequences and that copy numbers up to $\sim 500$ are readily obtained in a single transfection-selection experiment.

\section{Regulated gene expression by pMtn at varying copy number}

We examined both expression levels and metal regulation in the cell lines described above by measuring the product of the reporter gene galK. Cells were harvested before and after metal induction, and total cellular protein was analyzed by SDS-PAGE, followed by Western blot analysis using galK-specific antisera (Fig. 3). Alternatively, the cell extract was subjected directly to galK enzymatic assay. The recombinant galK product produced in these cells was found to be of the expected size, $41 \mathrm{kD}$, and to be fully active, indicating that Drosophila cells correctly express the bacterial gene. Moreover, galK expression now was subject to metal regulation. Addition of heavy metals resulted in a dramatic increase ( $\sim 50$-fold) of galK expression, as measured by radiograph scanning (Fig. 3) and dot blot analysis (data not shown). Most remarkably, all of the cells, including cell line C containing the very high copy number $(-500$ copies $)$ of the galK transcription unit, retained full regulation and expressed only very low or undetectable basal levels of galK in the uninduced state (Fig. 3).

To establish optimum induction conditions, the highcopy-number cell line $\mathrm{C}$ was induced using various concentrations of cadmium, copper, or zinc for different lengths of time. Maximum induction with cadmium occurred using $10 \mu \mathrm{M} \mathrm{CdCl}_{2}$ (Fig. 3), with product accumulation beginning about $4 \mathrm{hr}$ after the start of cadmium treatment and reaching a maximal level after $20 \mathrm{hr}$ of induction. This high level of galK synthesis could be maintained for 14 days of continuous induction. Copper was also an effective inducer but required a 20 -fold higher concentration of metal (i.e., $200 \mu \mathrm{M} \mathrm{CuSO}_{4}$ ) to reach maximum expression (Fig. 3). $\mathrm{ZnSO}_{4}$ also was tested for its inducing capability and was found to be a relatively poor inducer. We conclude that among the metals tested, cadmium was the most effective inducing agent and that the same high level of expression could be reached using a 20 -fold higher concentration of $\mathrm{CuSO}_{4}$. Further analysis indicated that cells could be maintained for up to 4 months in the presence of $10 \mu \mathrm{M} \mathrm{CdCl}_{2}$ or 200 $\mu \mathrm{M} \mathrm{CuSO}{ }_{4}$ without any apparent detrimental effect to growth and could maintain their fully induced levels of expression.

We also characterized the RNA induction levels and ratios of the three different cell lines $\mathrm{A}, \mathrm{B}$, and $\mathrm{C}$ car- 


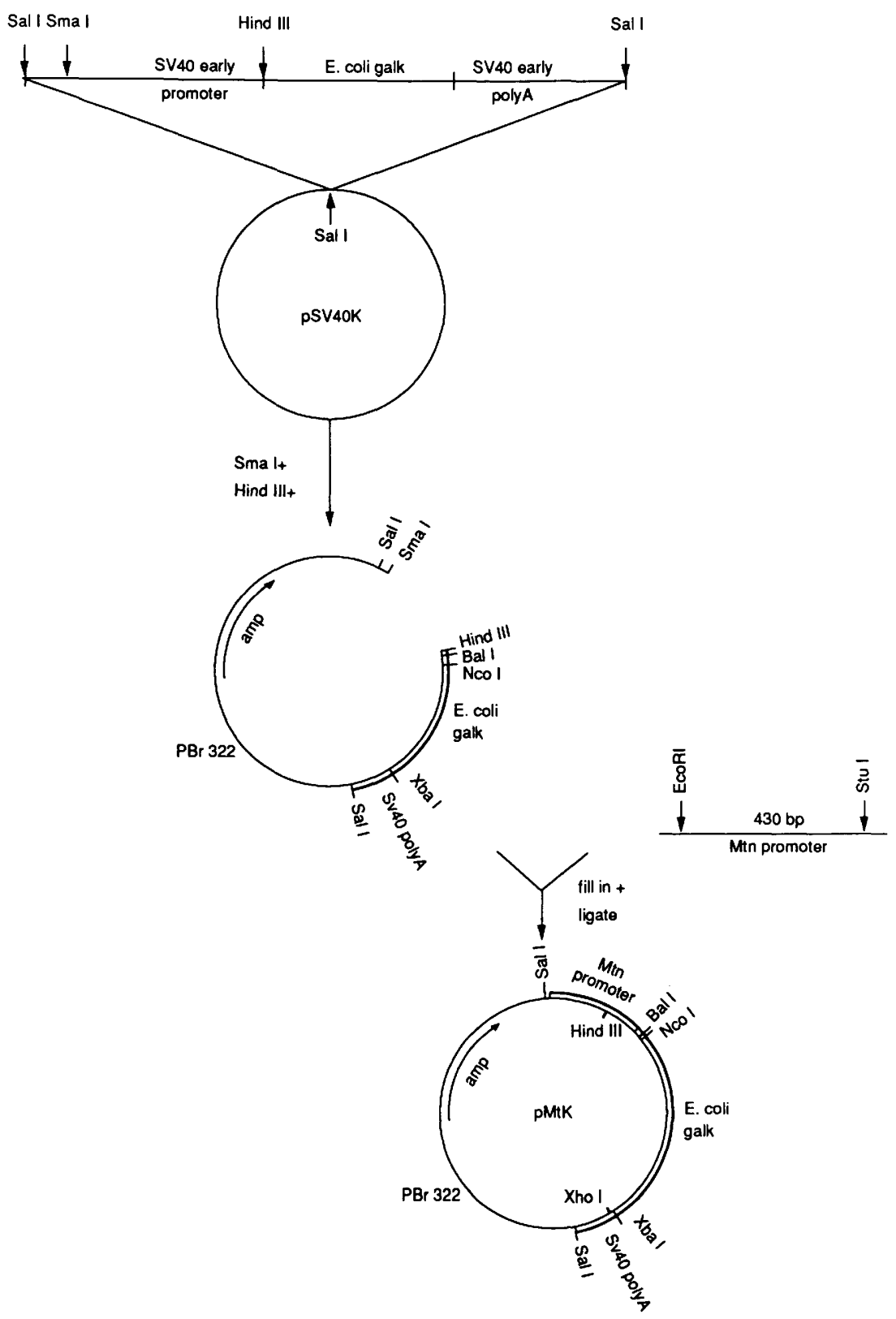

Figure 1. Construction of the pMtK vector. The pSV40K vector containing the E. coli galK gene fused to the SV40 promoter was digested with SmaI and HindIII, which excised the SV40 early promoter from the vector. The vector was subsequently end-filled and ligated to an end-filled 430-bp EcoRI-StuI fragment containing the D. melanogaster Mtn regulatory sequences. The Mtn promoter then was fused to the galK-coding sequences in such a fashion that the untranslated leader sequences consist of $60 \mathrm{bp}$ derived from the Mtn 5'-noncoding leader region fused to $70 \mathrm{bp}$ of the $5^{\prime}$ leader segment from the $E$. coli galK operon.

rying different copy numbers of the pMtn-galK transcription unit. Total cellular RNA was isolated as described in Methods from each cell line, both prior to and after cadmium induction. The RNA was analyzed by agarose-formaldehyde gel electrophoresis followed by Northern blotting and hybridization to a galK-specific probe. In each case, a transcript of the expected size, 1.5 $\mathrm{kb}$, was visualized. Figure 4 shows that cadmium induces a large accumulation of this galK RNA in the high-copy-number cell line C (lane 1), compared with relatively low, almost undetectable amounts of this RNA found in uninduced cells (lane 2). The RNA induction ratio was found to be $\sim 50$-fold using dot blot analysis of total RNA (data not shown). This induction ratio is consistent with that observed at the protein level. Cell lines A and B, containing low and medium copy numbers, respectively, showed similar results, except that lower amounts of total galK RNA and protein were found to accumulate after induction in approximate proportion to their relative copy number. 


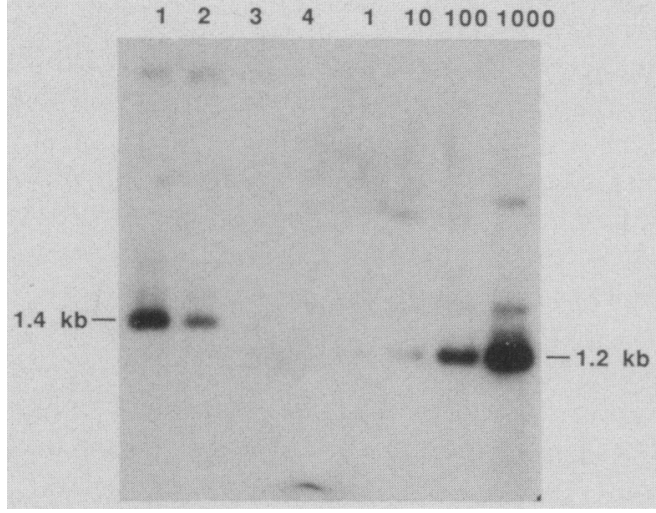

Figure 2. Determination of copy number. Southern analysis of genomic DNA from the methotrexate-resistant cell lines. One microgram of total DNA extracted from each cell line was digested with HindIII and XhoI, which excises the galK gene on a $1.4-\mathrm{kb}$ fragment. The samples were electrophoresed on a $1 \%$ agarose gel, and the DNA was transferred to nitrocellulose paper prior to hybridization with a $1.2-\mathrm{kb}^{32} \mathrm{P}$-labeled galK-spe-

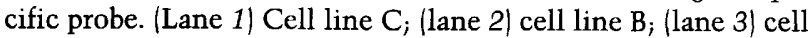
line A; (lane 4) untransformed control cells. The standard lanes $(1-4)$ contain the galK gene on a 1.2 -kb fragment loaded in exact amounts corresponding to $1,10,100$, and 1000 galK gene copies, respectively. Three independent analyses confirmed the copy numbers.

\section{Constitutive expression of the human $H$-ras oncogene} in Drosophila cells is lethal

Phylogenetically, the ras genes are among the most conserved oncogenes, and close homology is found in organisms ranging from yeast to man (Varmus 1984; Barbacid 1987). These genes are implicated in mammalian cell growth regulation, and point mutations resulting in single amino acid changes in the ras proteins are observed in a variety of tumor cells and tumor cell lines. Introduction of these mutant ras genes into cell lines that exhibit contact growth inhibition (e.g., NIH-3T3

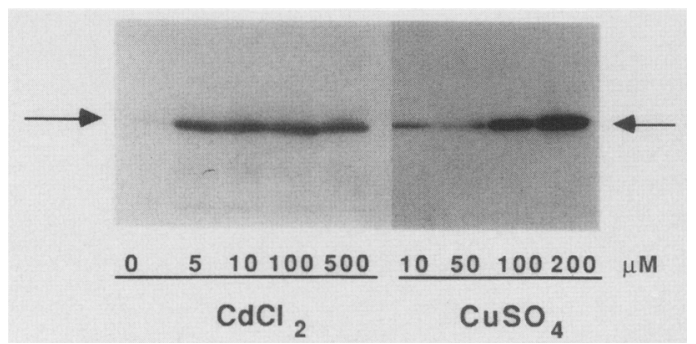

Figure 3. Induction of the Mtn promoter with copper and cadmium. Cells of cell line $\mathrm{C}\left(5 \times 10^{6}\right)$ were harvested after $20 \mathrm{hr}$ of exposure to various concentrations of $\mathrm{CdCl}_{2}$ or $\mathrm{CuSO}_{4}$, as indicated. The proteins were electrophoresed on $10 \%$ SDSPAGE and analyzed by Western blotting techniques. The galK protein was visualized using $g a l K$-specific antiserum followed by incubation with ${ }^{125} \mathrm{I}$-labeled protein A. Arrows indicate the position of the galK protein. Relative amounts of galK protein were determined by radiograph scanning. Similar results were obtained in repeated experiments.

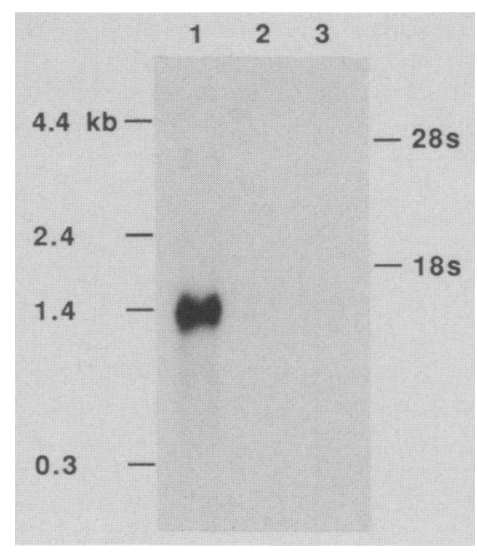

Figure 4. RNA analysis. Total RNA extracted from cell line $\mathrm{C}$ and control cells was subjected to Northern analysis. RNA extracted from $10^{6}$ cell.s was loaded in each lane. (Lane 1) Cell line C RNA (cells had been incubated with $10 \mu \mathrm{M} \mathrm{CdCl}$ for $24 \mathrm{hr}$ prior to harvesting; (lane 2) cell line C RNA; (lane 3) control cell line RNA (untransfected cells). The RNA was denatured with formaldehyde and run on a $1 \%$ denaturing agarose gel. The RNAs were transferred to nitrocellulose paper and hybridized to a $1.2-\mathrm{kb}^{32} \mathrm{P}$-labeled galK-specific probe. Repeated experiments were performed.

mouse cells) results in growth transformation (Pulciani et al. 1985). These transformed cells often show a reduced requirement for added growth factors and added serum supplements (Pulciani et al. 1985). The Drosophila S2 cell line is an immortalized cell line that requires relatively high serum levels (i.e., $10 \%$ fetal calf serum) for growth. In an attempt to examine the effect of ras on the growth properties of insect cells, we introduced and expressed both the wild-type H-ras and transforming VAL ${ }^{12}$ mutant human ras oncogene (T24 ras) into Drosophila $\$ 2$ cells. Initially we placed both the normal gene and the T24 mutant gene under the control of the copia $5^{\prime}$ LTR (pcodraswt and pcodT24) to achieve constitutive expression of these products in insect cells. pcodraswt and pcodT24 were introduced separately into S2 cells by cotransfection, with the pcodhygro vector containing the selectable marker for hygromycin $B$ resistance. A vector DNA ratio of 10 (pcodraswt or pcodT24) to 1 (pcodhygro) was chosen to obtain high copy number of the ras expression unit. Hygromycin-B-resistant transformants were selected and examined for ras gene expression. Only early on in the selection could ras expression be detected transiently in the polyclonal population. The vast majority of the cells did not recover from the selection and died. Plating efficiency experiments demonstrated a marked reduction in stable transformants compared to the control cell line (2; Table 1). Moreover, neither of the transformants expressed detectable levels of the ras protein. Southern blot analysis of genomic DNA showed that the cells did carry copies of either the normal or the T24 ras transcription unit integrated into the host genome (data not shown). However, both cell lines had lost the ability to express the recombinant product (Fig. 6B, lanes 4 and 5). 
Table 1. Plating efficiency

\begin{tabular}{lcc}
\hline $\begin{array}{l}\text { Cells } \\
\text { transfected } \\
\text { with }\end{array}$ & $\begin{array}{l}\text { Number of clones } \\
-\mathrm{CdCl}_{2}\end{array}$ & $\begin{array}{l}\text { Number of clones } \\
+\mathrm{CdCl}_{2}\end{array}$ \\
\hline pMT24 & 45 & 4 \\
pcodT24 & 2 & 30 \\
pcodhygro & 35 & \multicolumn{1}{c}{. } \\
\hline
\end{tabular}

The ras-transfected cells and control cells transfected with pcodhygro were plated in $0.3 \%$ soft agar containing M3 media $+300 \mu \mathrm{g} / \mathrm{ml}$ hygromycin $\mathrm{B} \pm 10 \mu \mathrm{M} \mathrm{CdCl}_{2}$. Three plates were seeded with $10^{6}$ cells for each transfection 7 days post-transfection, and colonies were counted 3 weeks later.

To prove that the copia-ras transcription unit constructed into the vector was indeed functional, we examined transient expression of the ras product from the same vectors. Cells were again transfected with the ras gene DNA constructs, but rather than being placed in selection for stable expression, they were analyzed 48-96 hr after transient transfection for ras expression. We found that both the normal and oncogenic ras forms were expressed and readily detected by this method (Fig. $6 \mathrm{C})$. Thus, the majority of the cells died only after prolonged selection under conditions of constitutive expression (i.e., several weeks), and those few cells that were obtained containing the 'competent' vector DNA did not express the gene product.

\section{Regulated expression of a lethal human oncogene}

In an attempt to circumvent this apparent toxicity or growth inhibition resulting from constitutive ras gene expression, we placed the normal and the T24 ras genes separately under the control of the Mtn promoter to create the vectors pMtraswt and pMT24, respectively, to achieve regulated expression of the gene products in S2 cells. Each vector construct was cotransfected with the pcodhygro vector, as described earlier in a ratio of $10: 1$, and resistant cell lines were selected. Southern blot analysis of the genomic DNA showed that the cells contained 20-25 copies of either the wild-type ras or T24 ras oncogene (Fig. 5, lanes 4 and 2). Then cells were examined for metal-inducible ras gene expression by protein immunoblot analysis. Efficient expression of both normal and oncogenic forms of ras could now be obtained after induction with $10 \mu \mathrm{M} \mathrm{CdCl}_{2}$ (Fig. 6). We estimate by dot blot analysis that after $20 \mathrm{hr}$ of induction, ras expression could account for $\sim 0.2-0.5 \%$ of the total cellular protein. Moreover, these cells could be carried in culture under selection in the uninduced state for $>10$ months and they remained fully inducible for ras expression (Fig. 6B, lane 1). In contrast, if these cultures were maintained under permanent $\mathrm{Cd}$ induction and under selection for several weeks, a dramatic loss in ras expression was observed (Fig. 6A). This confirms the growth-inhibitory effect of constitutive expression of ras in this cell type. Southern blot analysis of the cells before and after permanent $\mathrm{Cd}$ induction showed that, at least in part, the loss of ras expression resulted from reduction of the number of integrated ras DNA sequences in the induced cell population (Fig. 5, lanes 3 and 5). Our results clearly demonstrate that expression of both the normal and the mutant ras gene is toxic or at least growth static in Drosophila S2 cells and that cell lines containing high copy numbers of a competent transcription unit for this gene can be maintained only by using a regulatable promoter system.

It was somewhat surprising that expression of the human ras oncogene in this serum-dependent embryonic cell line was growth inhibitory rather than growth stimulating, as it appears to be in many mammalian and avian cell types. However, for at least one mammalian cell line, ras expression has been shown to arrest growth (Hirakawa and Ruley 1988). Our results in Drosophila mimic these results, as well as those observed both in wild-type yeast cells expressing a chimeric mammalian/ yeast ras oncogene (Kataoka et al. 1985) and in Dictyostelium transformed with an oncogenic form of the ras gene. In both cases, efficient ras expression was shown to be a lethal or growth-arresting event (Reymond et al. 1986).

\section{Methods}

\section{Vector construction}

pSV40K was constructed by ligating a 1780-bp Sall cassette containing the galK transcription unit into a Sall-cut pML2 plasmid. [pML2 is a pBR322 derivative that has deleted the poison-minus sequence and a portion of the tetracycline-resistant gene (Mellon et al. 1981)]. The SalI cassette contained the SV40 early promoter, the E. coli galK gene, and the SV40 early polyadenylation site. A HindIII site positioned downstream of

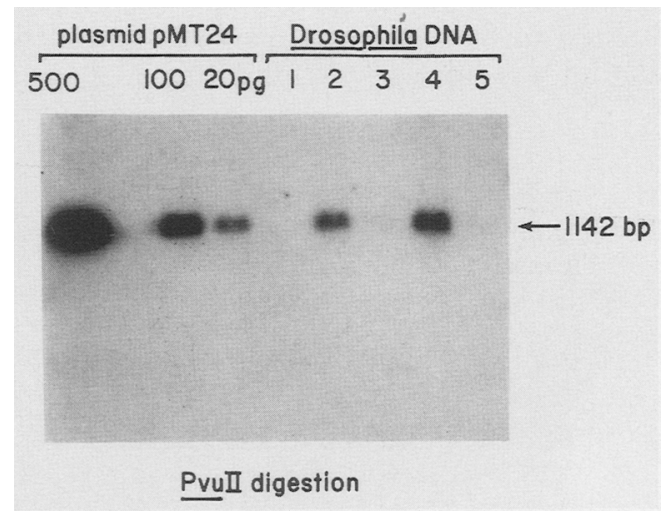

Figure 5. DNA analysis of ras transfected cells. High-molecular-weight DNA was extracted from cells before or after 2.5 months of cadmium induction. DNA (250 ng) was digested with PvuII, which excises the ras gene from the vector, electrophoresed on a $0.8 \%$ agarose gel, and transferred onto a nitrocellulose filter. The presence of integrated genes in the host DNA was detected with a ${ }^{32} \mathrm{P}$-nick-translated ras probe. (Lane 1) Control lane; (lanes 2 and 4) pMT24- and pMtraswt-transfected cells; (lanes 3 and 5) same cultures after 2.5 months under cadmium induction. 

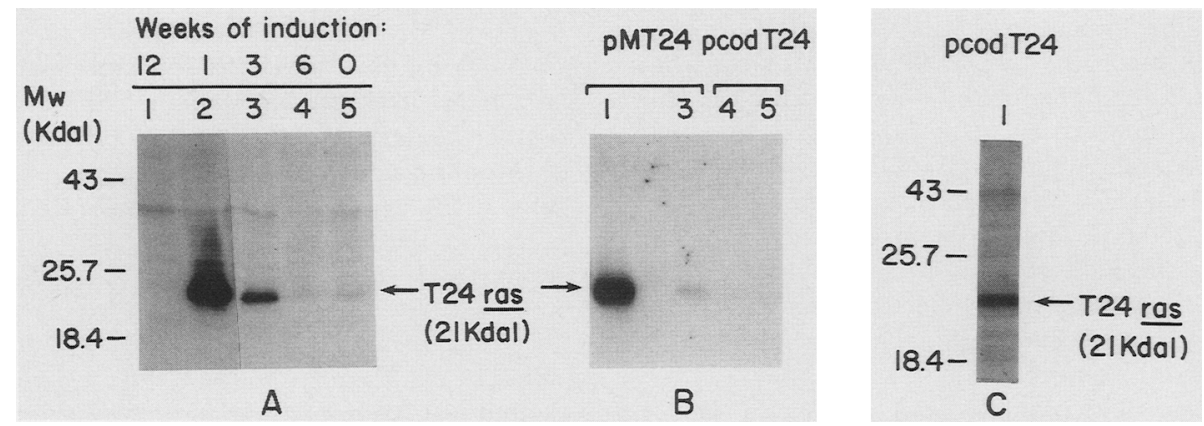

Figure 6. Loss of T24 ras expression under permanent induction of the Mtn promoter. $|A|$ pMT24-transfected cells were seeded in complete medium containing $10 \mu \mathrm{M} \mathrm{CdCl}_{2}$. Protein extracts $(30 \mu \mathrm{g})$ from the cells before (lane 5) and after 1 week (lane 2), 3 weeks (lane 3), 6 weeks (lane 4), and 12 weeks (lane 1) of induction were analyzed on 15\% SDS-PAGE and transferred onto a nitrocellulose filter. The filter was subsequently treated with anti-ras antiserum followed by incubation with ${ }^{125}$ I-labeled protein A. $(B)$ pMT24transfected cells were maintained in culture for 10 months and were induced for $48 \mathrm{hr}$ with $10 \mu \mathrm{M} \mathrm{CdCl}{ }_{2}$ (lane 1 ) or uninduced (lane 3) and analyzed as in $A$. Survivors from pcodT24-transfected cultures were analyzed for constitutive expression (lanes 4 and 5). (C) Cells were transfected transiently. The precipitate was left on the cells for $96 \mathrm{hr}$ before the cells were harvested and analyzed, as in $B$. (Lane 1) $30 \mu \mathrm{g}$ protein extract from pcodT24-transfected cells.

the SV40 promoter was destroyed, leaving a unique HindIII site between the SV40 promoter and the galK gene (Fig. 1).

pMtK was derived from pSV40K by removing the SV40 promoter with a SmaI plus HindIII digestion and end-filling and replacing it with an EcoRI-StuI end-filled 430-bp fragment containing the Drosophila Mtn promoter. The promoter sequence spans from $370 \mathrm{bp}$ upstream to $50 \mathrm{bp}$ downstream of the initiation site of transcription. The fragment contains all the regulatory sequences needed for metal-regulated expression of the Mtn gene in Drosophila flies (Fig. 1).

pMT24 is a derivative of a pucl8 vector that carries a transcription unit composed of the thymidine kinase promoter, the mutant T24 ras gene, and the SV40 early polyadenylation site inserted between the PstI site and the BamHI site. The thymidine kinase promoter was excised by digestion with BglII followed by a fill-in reaction and a subsequent digestion with AatII and was replaced by a 430-bp EcoRI-StuI Drosophila Mtn promoter fragment ligated to an AatII-EcoRI linker.

pMtraswt is also a derivative of a pBR322 vector carrying a transcription unit composed of the thymidine kinase promoter, the wild-type ras gene, and the SV40 early polyadenylation site. The thymidine kinase promoter was replaced by the Mtn promoter in similar fashion as described above.

pcodT2 4 was constructed as follows: The T24 ras gene then was moved into a pucl 8 derivative, pucopiadATG, carrying the copia 5'LTR inserted at the BamHI site. The T24 ras gene and SV40 early poly(A) site were isolated from pTKT24 ras on a $B g I I I-E c o R I$ fragment and were inserted immediately downstream of the copia 5'LTR into a BgIII-EcoRI-digested vector.

pcodraswt was constructed from pcodT24 by excising the T24 ras gene using HindIII-BamHI digestion and replacing it with the wild-type ras wild-type gene on a HindIII-BamHI fragment.

\section{Stable and transient transformation}

The D. melanogaster Schneider 2 cell line (Schneider 1972) was maintained in M3 medium (Lindquist et al. 1982), supplemented with $10 \%$ fetal bovine serum that was heat-inactivated at $65^{\circ} \mathrm{C}$ for $30 \mathrm{~min}$. Cells were grown in Corning flasks at $25^{\circ} \mathrm{C}$. For DNA transfection, $3 \times 10^{6}$ cells seeded in $4 \mathrm{ml}$ of medium the previous day were cotransfected with $20 \mu \mathrm{g}$ of plasmid DNA using calcium phosphate precipitation, as described by
Wigler et al. (1979). The cotransfection cocktail contained a mixture of the vector that contained the gene of interest and a vector containing a selectable marker, being either pHGCO containing the E. coli dhfr gene (Bourouis and Bruno 1983; Moss 1985 ) or pcodhygro containing the E. coli hygromycin B phosphotransferase gene (Van der Straten et al. 1987; 1989). At 15-18 hr post-transfection the cells were spun down, washed twice with M3 medium, and resuspended in $5 \mathrm{ml}$ of fresh M3 medium. After 2 days, the cells were spun down and resuspended in selective medium containing either methotrexate $(100 \mathrm{ng} / \mathrm{ml})$ or hygromycin B $(300 \mu \mathrm{g} / \mathrm{ml})$, depending on the cotransfected plasmids. Selective medium was replaced every 5 days, and stably transformed polyclonal cell populations were isolated after 3 or 6 weeks of selection with hygromycin B or methotrexate, respectively. Hygromycin B was maintained routinely in the media at all times after selection.

For transient expression, cells were transfected as above, except no vector containing a selective marker gene was included in the transfection mixture. The precipitate was left on the cells for up to 5 days until harvest.

\section{Inductions}

We have analyzed and determined the optimum induction procedures for the Mtn promoter. Both transiently and stably transformed cells were induced routinely by the addition of 10 $\mu \mathrm{M} \mathrm{CdCl} 2$ or $200 \mu \mathrm{M} \mathrm{CuSO}$ to the culture medium for $20 \mathrm{hr}$.

\section{Northern analysis of $m R N A$ levels}

Total cellular RNA was isolated as described previously (McGarry and Lindquist 1985). Samples were denatured with formaldehyde and separated on 1\% agarose-formaldehyde gel, transferred to nitrocellulose, and hybridized to a galK-specific nick-translated probe according to Maniatis et al. (1982).

\section{Southern analysis of integrated DNA}

Total DNA was prepared by direct lysis of Drosophila cells in $0.1 \mathrm{M} \mathrm{NaCl}_{2}, 0.01 \mathrm{M}$ Tris (pH 8.0), and $1 \mathrm{mM}$ EDTA (final $\mathrm{pH}$ 7.5 ), at a concentration of $10^{8}$ cells per milliliter. The solution was brought to a final concentration of $20 \mathrm{~mm}$ EDTA and $0.2 \%$ SDS. RNase was added at $100 \mu \mathrm{g} / \mathrm{ml}$, and the reaction was in- 
cubated at $37^{\circ} \mathrm{C}$ for $2 \mathrm{hr}$. Proteinase $\mathrm{K}$ was added at $100 \mu \mathrm{g} / \mathrm{ml}$, and the reaction was incubated further for $2 \mathrm{hr}$ at $37^{\circ} \mathrm{C}$. The solution was extracted with phenol chloroform until clean interface, and the high-molecular-weight DNA was collected with a sterile tip after ethanol precipitation. The DNA was resuspended into a Tris-EDTA buffer and quantitated by measuring absorbance at $260 \mathrm{~nm}$. After restriction with HindIII and $X h o I$, which excises the galK transcription unit on a $1.4-\mathrm{kb}$ fragment, the DNA was subject to electrophoresis on $1 \%$ agarose gel in standard Tris-borate buffer. Transfer onto nitrocellulose filter and hybridization to a galK-specific nick-translated probe were according to Maniatis et al. (1982).

\section{Protein analysis}

Total cellular proteins were separated on $10 \%$ SDS-polyacrylamide slab gels, and the galK and ras proteins were detected by Western blotting analysis (Gross et al. 1985) using galK- and ras-specific rabbit antiserum followed by incubation with ${ }^{125} \mathrm{I}$ labeled protein A (National Cancer Institute).

DNA restriction enzymes were purchased from New England Biolabs or Boehringer-Mannheim, and reactions were carried out according to manufacturers' instructions.

\section{Acknowledgments}

We thank Peter Sherbas for donation of the Drosophila S2 cell line and for giving advice on transfection, and we appreciate the effort of Allan Shatzman in giving helpful comments on the manuscript.

\section{References}

Barbacid, M. 1987. ras genes. Annu. Rev. Biochem. 56: 779827.

Bourouis, M. and J. Bruno. 1983. Vectors containing a prokaryotic dihydrofolate reductase gene transform Drosophila cells to methotrexate-resistance. EMBO I. 2: 1099-1104.

Brinster, R.L., H.Y. Chen, R. Warren, A. Sarthy, and R.D. Palmiter. 1982. Regulation of metallothionein-thymidine kinase fusion plasmids injected into mouse eggs. Nature 296: 39-42.

Bunch, T., Y. Grinblat, and L.S.B. Goldstein. 1988. Characterization and use of the Drosophila metallothionein promoter in cultured Drosophila melanogaster cells. Nucleic Acid Res. 16: 1043-1059.

Durnam, D.M. and R.D. Palmiter. 1981. Transcriptional regulation of the mouse metallothionein-I gene by heavy metals. $J$. Biol. Chem. 256: 5712-5716.

Gross, M., R.W. Sweet, G. Sathe, S. Yokoyama, O. Fasano, M. Goldfarb, M. Wigler, and M. Rosenberg. 1985. Purification and characterization of human $\mathrm{H}$-ras proteins expressed in Escherichia coli. Mol. Cell. Biol. 5: 1015-1025.

Hamer, D.H. 1986. Metallothioneins. Annu. Rev. Biochem. 55: 913-951.

Hamer, D.H. and M. Walling. 1982. Regulation in vivo of a cloned mammalian gene: Cadmium induces the transcription of a mouse metallothionein gene in SV40 vectors. $J$. Mol. Appl. Genet. 1: 273-288.

Hirakawa, T. and H. Earl Ruley. 1988. Rescue of cells from ras oncogene-induced growth arrest by a second, complementing, oncogene. Proc. Natl. Acad. Sci. 85: 1519-1523.

Hsiung, N., R. Fitts, S. Wilson, A. Milne, and D. Hamer. 1984. Efficient production of hepatitis B surface antigen using a bovine pappaloma virus metallothionein vector. J. Mol. Appl. Genet. 2: 497-506.
Johansen, H., M. Reff, D. Schumperli, and M. Rosenberg. 1984. Studying eukaryotic transcription and translation by gene fusion. In Gene expression, The Alfred Benzon, 19 led. B.F.C. Clark, H. Peterson, and J.H. Thaysen), pp. 413-429. Munksgaarad Press, Copenhagen.

Kagi, J.H.R. and Y. Kojima, eds. 1987. Metallothionein II. Birkhauser Verlag, Basel.

Kamerow, H.N., C.R. Merril, and W.G. Nash. 1981. Absence of galactose enzyme activities in axenic Drosophila melanogaster. Insect Biochem. 11: 221-224.

Karin, M., G. Cathala, and M.C. Nguyen-Huu. 1983. Expression and regulation of a human metallothionein gene carried on an autonomously replicating shuttle vector. Proc. Natl. Acad. Sci. 80: 4040-4044.

Karin, M., A. Haslinger, H. Holtgreve, R.I. Richards, P. Krauter, H.W. Westphal, and M. Beato. 1984. Characterization of DNA sequences through which cadmium and glucocorticoid hormones induce human metallothionein-IIA gene. Nature 308: 513-520.

Kataoka, T., S. Powers, S. Cameron, O. Fasano, M. Goldfarb, J. Broach, and M. Wigler. 1985. Functional homology of mammalian and yeast ras genes. Cell 40: 19-26.

Lastowsky-Perry, D., E. Otto, and G. Maroni. 1985. Nucleotide sequence and expression of a Drosophila metallothionein. I. Biol. Chem. 260: 1527-1530.

Lindquist, S., S. Sonoedo, T. Cox, and K. Slusser. 1982. Instant medium for Drosophila tissue culture cells. Drosophila Inf. Serv. 58: 163-164.

Maniatis, T., E.F. Fritsch, and J. Sambrook. 1982. Molecular cloning: A laboratory manual. Cold Spring Harbor Laboratory, Cold Spring Harbor, New York.

Maroni, G., E. Otto, and D. Lastowsky-Perry. 1985. Molecular and cytogenetic characterization of a metallothionein gene of Drosophila. Genetics 112: 493-504.

Mayo, K.E., R. Warren, and R.D. Palmiter. 1982. The mouse metallothionein-I gene is transcriptionally regulated by cadmium following transfection into human or mouse cells. Cell 2: 99-108.

McGarry, T.J. and S. Lindquist. 1985. The preferential translation of Drosophila hsp70 mRNA requires sequences in the untranslated leader. Cell 42: 903-911.

Mellon, P., V. Parker, Y. Glusman, and T. Maniatais. 1981. Identification of DNA sequences required for transcription of the human $\alpha$-globin gene in a new SV40 host-vector system. Cell 27: 279-288.

Moss, R.E. 1985. "Analysis of a transfection system for Drosophila tissue culture cells." Ph.D. thesis. Harvard University, Cambridge.

Otto, E., J.E. Young, and G. Maroni. 1986. Structure and expression of a tandem duplication of the Drosophila metallothionein gene. Proc. Natl. Acad. Sci. 83: 6025-6029.

Otto, E., J.M. Allen, J.E. Young, R.D. Palmiter, and G. Maroni. 1987. A DNA segment controlling metal-regulated expression of the Drosophila melanogaster metallothionein gene Mtn. Mol. Cell. Biol. 7: 1710-1715.

Pavalakis, G. and D.H. Mamer. 1983. Regulation of a metallothionein-growth hormone hybrid gene in bovine papilloma virus. Proc. Natl. Acad. Sci. 80: 397-401.

Pulciani, S., E. Santos, L.K. Long, V. Sorrentino, and M. Barbacid. 1985. ras gene amplification and malignant transformation. Mol. Cell. Biol. 5: 2836-2841.

Reymond, D.C., R.H. Gomer, W. Nellen, A. Theibert, P. Devreotes, and R.A. Firtel. 1986. Phenotypic changes induced by a mutated ras gene during development of Dictyostelium transformants. Nature 323: 340-343.

Sambrook, J., L. Rodgers, J. White, and M.J. Gething. 1985. 
Lines of BPV-transformed murine cells that constitutively express influenza hemagglutinin. EMBO /. 4: 91-103.

Schneider, I. 1972. Cell lines derived from late embryonic stages of Drosophila melanogaster. J. Embryol. Exp. Morphol. 27: 353-356.

Searle, P.F., B.L. Davidson, G.W. Stuart, T.M. Wilkie, G. Norstedt, and R.D. Palmiter. 1984. Regulation, linkage, and sequence of mouse metallothionein I and II genes. Mol. Cell. Biol. 4: $1221-1230$.

Van der Straten, A., H. Johansen, R. Sweet, and M. Rosenberg. 1987. Efficient expression of foreign genes in cultured Drosophila melanogaster cells using hygromycin B selection. In Invertebrate cell systems applications, 1987, (ed. Jun Mitsuhashi|, vol. 1, CRC Press, Boca Raton.

Van der Straten, A., H. Johansen, M. Rosenberg, and R. Sweet. 1989. Novel hygromycin B selection system for the overexpression of a heterologous gene in Drosophila melanogaster cultured cells. Curr. Methods Mol. Biol. 1: 1-8.

Varmus, H.E. 1984. The molecular genetics of cellular oncogenes. Annu. Rev. Biochem. 5: 2836-2842.

Wigler, M., A. Pellicer, S. Silverstein, R. Axel, G. Urlaub, and L. Chasin. 1979. DNA-mediated transfer of the adenine phosphoribosyltransferase locus into mammalian cells. Proc. Natl. Acad. Sci. 76: 1373-1376. 


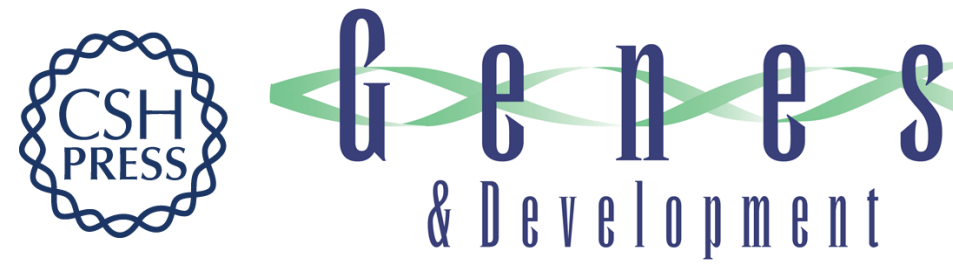

\section{Regulated expression at high copy number allows production of a growth-inhibitory oncogene product in Drosophila Schneider cells.}

H Johansen, A van der Straten, R Sweet, et al.

Genes Dev. 1989, 3:

Access the most recent version at doi:10.1101/gad.3.6.882

References This article cites 31 articles, 11 of which can be accessed free at:

http://genesdev.cshlp.org/content/3/6/882.full.html\#ref-list-1

License

Email Alerting

Service

Receive free email alerts when new articles cite this article - sign up in the box at the top right corner of the article or click here.

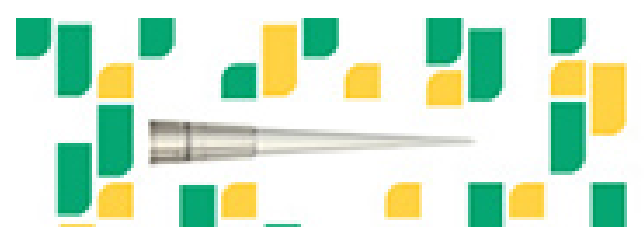

Focused on your science. 